\title{
SYSTEM FOR COOPERATIVE MOVEMENTS OF ROV AND ITS SUPPORTING VESSEL
}

\author{
Vladimir Filaretov, Alexander Konoplin \& Nikita Konoplin
}
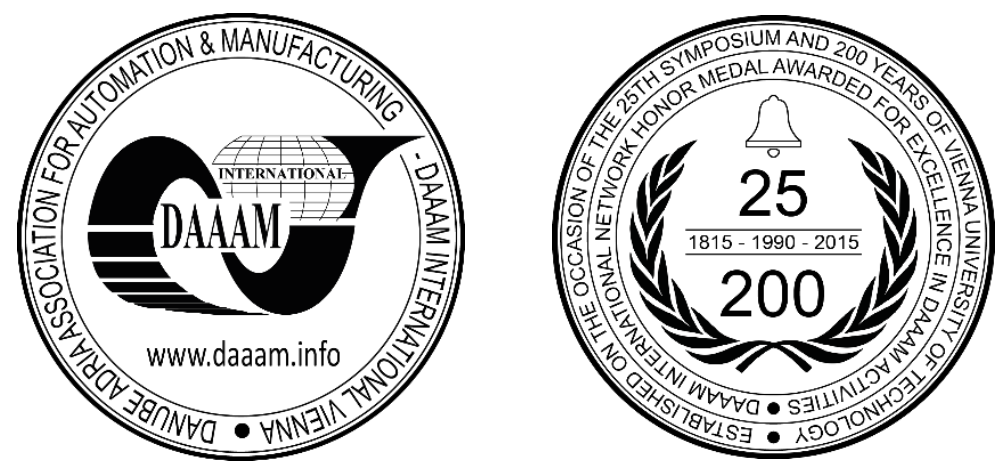

This Publication has to be referred as: Filaretov, V[ladimir] F[edorovich]; Konoplin, A[lexander] \& Konoplin, N[ikita] (2017). System for Cooperative Movements of ROV and its Supporting Vessel, Proceedings of the 28th DAAAM International Symposium, pp.0513-0516, B. Katalinic (Ed.), Published by DAAAM International, ISBN 978-3-90273411-2, ISSN 1726-9679, Vienna, Austria

DOI: $10.2507 / 28$ th.daaam.proceedings.072

\begin{abstract}
The work proposes an intelligent system that automatically generates warnings and recommendations for the operators implementing coordinated movements of the remote operated vehicle, the supporting vessel and the lifting equipment in the process of underwater operations. The recommendations are formed on the basis of the continuous analysis of the current relative position of the supporting vessel, the remote operated vehicle and its depressor-weight, the seabed relief and the desired route of this vehicle. The proposed system provides information and intellectual support for the operators, this allows to significantly improve the accuracy and speed of the performing of complex and expensive underwater operations, excluding the emergency situations.
\end{abstract}

Keywords: intelligent system; remote operated vehicle; supporting system; underwater operations; expert system

\section{Introduction}

Remote operated underwater vehicles (ROV) are indispensable means of effectively solving of research, technological and rescue tasks in the depths of the World Ocean. At the present time, the high-precision navigation systems have been created, as well as the control systems for ROVs and supporting vessels [1,2]. The intermediate depressor-weight is used in deep water, it connects the thick cable of the supporting vessel with the flexible cable of the ROV. The flexible cable provides the high mobility of the ROV. However, the tension of the flexible floating cable can occur under unknown currents unexpectedly for the operator [3,4]. This tension limits the movement and working area of the ROV equipped with even a powerful propulsion-steering complex. In addition, the depressor-weight can often collide with the ground creating an emergency situation, which can lead to the breakage of the flexible cable. All this complicates the operation of the ROV at great depths and reduces the efficiency of the working operations performing.

It is necessary to simultaneously and consistently control the ROV and the supporting vessel to eliminate these emergency situations when the ROV moving along a given route. It is also necessary to control the length of the thick cable, constantly monitoring the relative position of the ROV and the depressor-weight and completely eliminating the collision of the depressor-weight with the ground. 
The works and experiments with ROV Sub-Atlantic Comanche 18 in deep-sea expeditions in the Japanese Sea, the Okhotsk Sea and the Bering Sea have shown that the realization of relatively accurate coordinated movements of the supporting vessel, ROV and its depressor-weight in manual mode is almost impossible. In addition, this work has a great psychological burden to the operator and often leads to long delays in the performance of the scientific research and technological underwater operations.

The work deals to the developing a method for synthesizing an intelligent system to support the activities of operators to successfully solve the above problem. This system will be used for the precise coordinated movement of the supporting vessel, ROV and its depressor-weight in order to ensure the trouble-free movement of these objects during the performing of the underwater works.

\section{The algorithm for control of coordinated movements of the ROV and the depressor-weight}

The beacons of the sonar navigation system with an ultrashort base are installed on the ROV and its depressor-weight to determine their relative position. The antenna of sonar navigation system is fixed on a supporting vessel equipped with a dynamic positioning system [5]. The ROV work is possible only when the working object or the route target point is in the working area of the ROV, the dimensions of the working area are determined by the length of the flexible floating cable (see Fig. 1). The space location of the working area of ROV is determined by the location of the depressor-weight held by the thick cable of the supporting vessel. When the ROV, which is moving to the target point, approaches to the boundaries of its working area by the distance $k$, the developed algorithm calculates the direction and value $l$ of the supporting vessel displacement for the movement of the depressor-weight towards the ROV. This displacement allows for the greatest freedom of maneuvering of the ROV.

At the same time, using the developed algorithm, the program signals are calculated for controlling the lifting device for holding the depressor-weight above the ROV on the desired value $h$ (see Fig. 1). The calculations are made taking into account the relative location and direction of the movements of the supporting vessel, positions of the ROV and its depressor-weight and also the complexity of the bottom surface relief determined by the absolute Doppler lag using the method described in the works $[6,7]$. The variable value $h$ allows to efficient operate the ROV, excepting situations in which the depressor-weight and the flexible communication cable collides with the bottom.

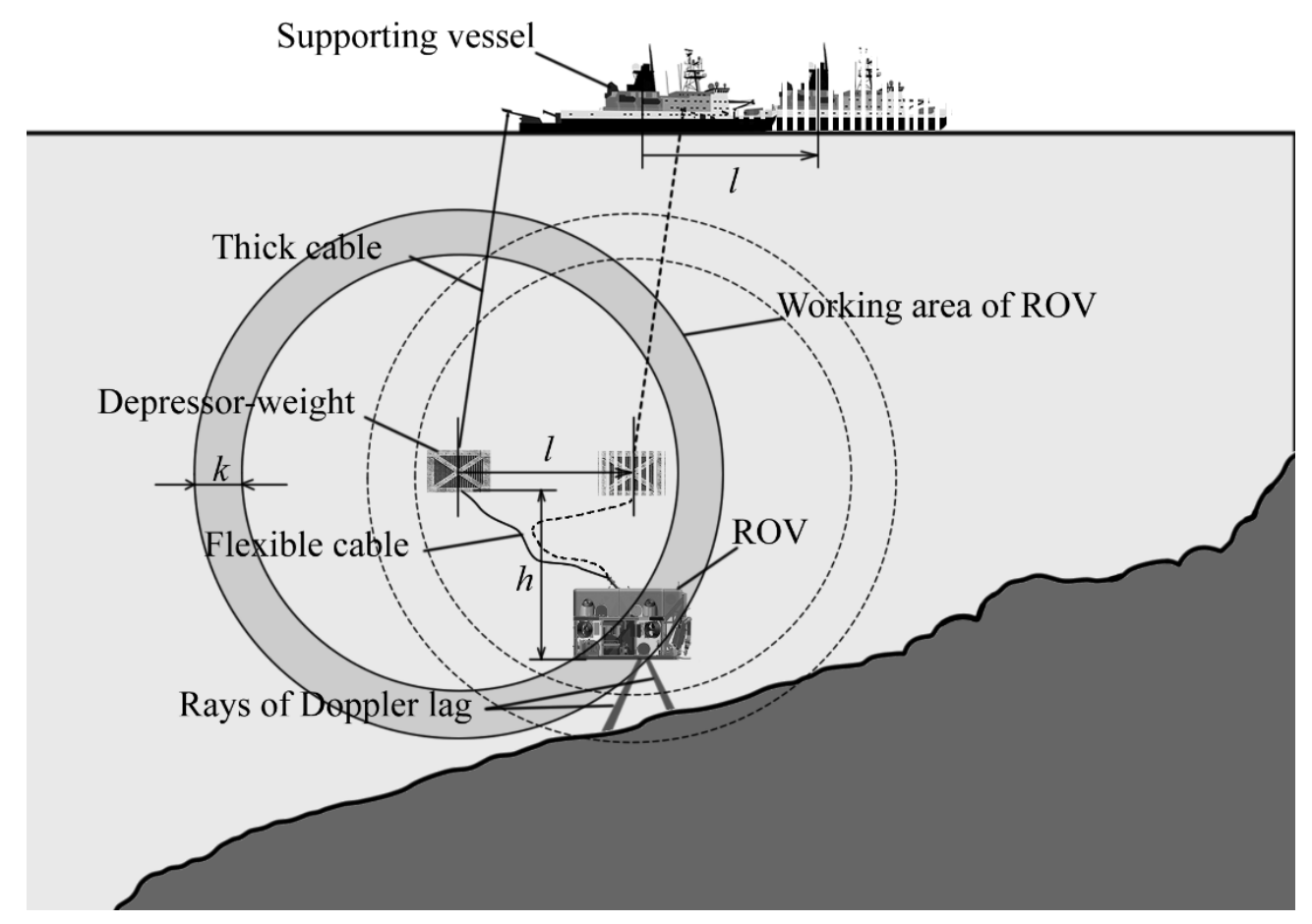

Fig. 1. Controlled underwater complex

\section{Features of the developed system architecture}

The architecture of the proposed intelligent system is shown on Fig. 2. This architecture allows to provide the operators with visual recommendations and warnings generated in real time on the basis of the expert evaluation of the information obtained from various sensors and navigation systems from different manufacturers.

The developed algorithm for the calculation of the values $l$ and $h$, which determines the required location of the depressor-weight of the ROV when it approaches at the distance $k$ to the boundaries of the working area, is realized in the decision-making system. Moreover, the variable $k$ is given by this system on the basis of the formalizes estimates of underwater operation conditions stored in the expert knowledge database. These estimates are set by the operator or 
determined automatically based on the information from the sensors and also using the algorithm for determining the complexity of the bottom surface relief [7]. Wherein, the accumulated experience of the consequences of the choice of the particular value $k$ is taken into account.

In addition, according to the scheme (see Fig. 2), the decision-making system compares the current data received from the sensors and external devices with the data of the base of formalized safety representations, such as: emergency tension of the flexible cable; complex relief of the bottom surface; possibility of the collision of the depressor-weight to the bottom or ROV. In this case, the possibility of an emergency situation is identified and the warnings and alarms for operators are implemented.

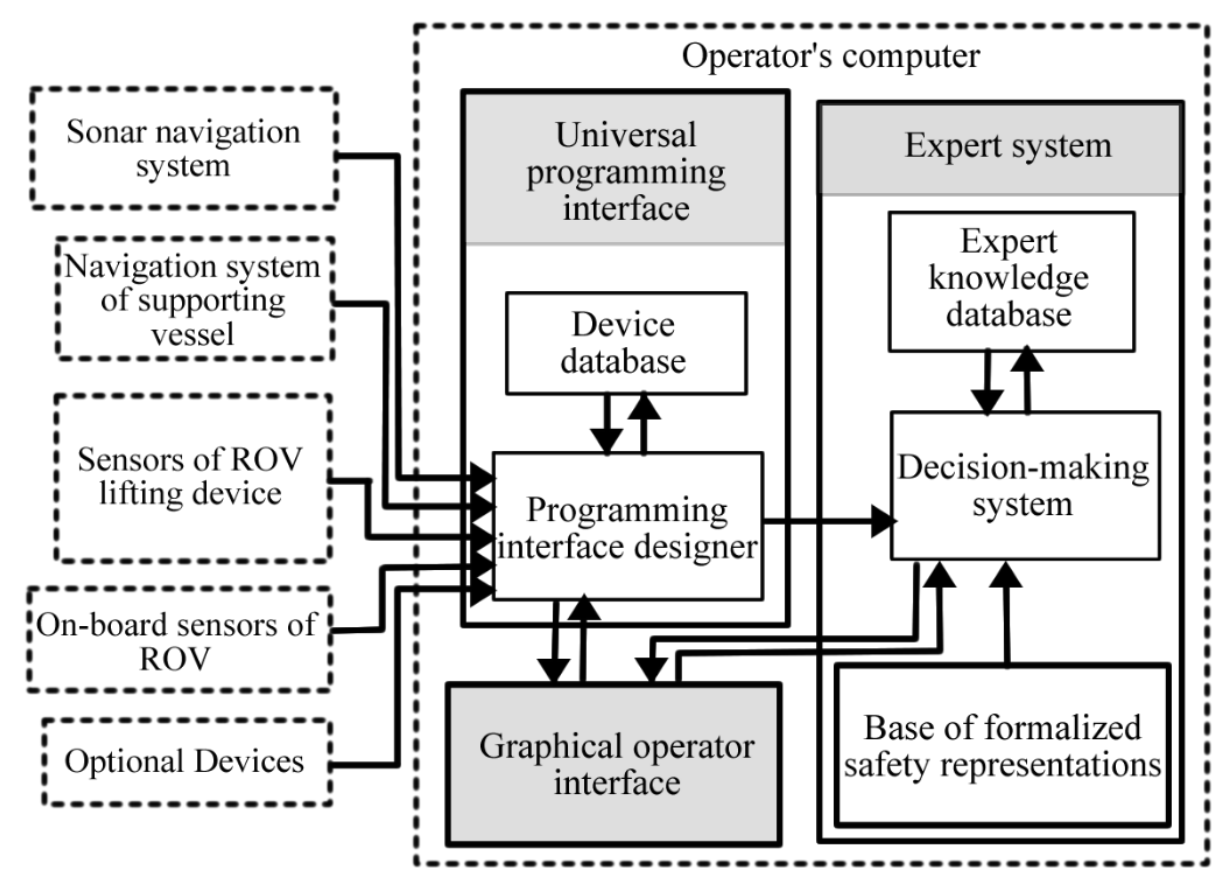

Fig. 2. Structural diagram of the intelligent system

The recommendations and warnings generated by the decision-making system are graphically displayed by the graphical operator interface. This interface has all the properties of the interface of the typical information-control system [8] of the ROV and provides the formation of the maps, as well as the routes planning for the ROV and the supporting vessel.

Since the navigation systems, ROV sensors and sensors of the lifting device require the using of various algorithms for processing data from these devices, then the universal programming interface is proposed to use for the devices communication with the expert system and the graphical operator interface. The programming interface designer using the device database converts the information received from various devices into a universal form, which used by both the expert system and the graphical operator interface. For this, the software implementations of data exchange interfaces for each device, as well as the software implementations of functional algorithms and data processing mechanisms are recorded in the device database.

As a result, the developed architecture will allow to create the software implementation of the intelligent system for the supporting of the activities of operators of ROVs. This system will not require the changes of the expert system and the graphical operator interface in case of the changing of the configuration and composition of devices and sensors, as well as the changing of the processing algorithms of the received data.

\section{Conclusion}

The paper suggests the system that automatically generates recommendations and warnings to the operators of ROVs for the most efficient control of a supporting vessel, ROV, as well as a lifting device. The system uses the expert estimates of the current relative position of the supporting vessel, the ROV and its depressor-weight, the bottom surface relief, the desired route of the vehicle, and the accumulated knowledge of the prerequisites, causes and consequences of emergency situations. The using of the created system will improve the accuracy and speed of the performing of complex and expensive underwater operations, as well as allows to eliminate the occurrence of emergency situations.

Currently, work is underway to establish an intellectual system for the supporting of the operators of the ROV SubAtlantic Comanche 18, which is based on the supporting vessel "Akademik M.A. Lavrentyev". The system will be tested in the deep-sea scientific research expedition of the National Scientific Center of Marine Biology FEB RAS in the Bering Sea in 2018. 


\section{Acknowledgments}

This work was performed in Institute of Marine Technology Problems FEB RAS, Institute for Automation and Control Processes FEB RAS, Far Eastern Federal University and also in National Scientific Center of Marine Biology FEB RAS (Vladivostok, Russia).

The development and software implementation of the intelligent system for supporting of activities of ROV operators was carried out with the financial support of the Russian Science Foundation (RSF) grant (project №17-79-10064). The algorithm for control of coordinated movements of the ROV and the depressor-weight was developed with the financial support of the Russian Foundation for Basic Research (RFBR) grant (project 16-29-04195 Ofi_m).

\section{References}

[1] Scherbatyuk, A.F., Dubrovin F.S., Rodionov A.Yu., Unru P.P. (2016). Group Navigation and Control for Marine Autonomous Robotic Complex Based on Hydroacoustic Communication // Proceedings of the 2016 IEEE/RSJ International Conference on Intelligent Robots and Systems (IROS), Deajeon, - pp. 1388 - 1393.

[2] Conte G., Scaradozzi D., Mannocchi D., Raspa P., Panebianco L., Screpanti L. (2016). Experimental testing of a cooperative ASV-ROV multi-agent system // IFAC-PapersOnLine, Toulouse, France, Vol. 49, Iss. 23, - pp. 347354.

[3] Kostenko V.V., Mokeeva I.G. (2009). Research of Tie Cable Influence on ROV's Manoeuvrability. Underwater Research and Robotics, № 1(7). - pp. 22-27. (Костенко В.В., Мокеева И.Г. Исследование влияния кабеля связи на маневренность телеуправляемого подводного аппарата // Подводные исследования и робототехника. 2009. № 1(7). - C. 22-27.)

[4] Rulevsky V.M., Yudintsev A.G. (2013). Power Supply Systems for Modern Remote-controlled Unmanned Underwater Vehicles // Proc. of 5th All-Russian Scientific and Technical Conf. "Technical problems of development of the World Ocean", Vladivostok, - pp. 81-86. (Рулевский В.М., Юдинцев А.Г. Системы электропитания современных телеуправляемых необитаемых подводных аппаратов // Материалы 5-й Всероссийской научно-технической конф. «Технические проблемы освоения мирового океана», Владивосток, 2013. - С. 8186.)

[5] Zanin V.Yu. (2010). Using a Underwater Remote Operating Vehicle (ROV) with Specialized and Non-specialized Ships. News of SFedU. Technical science, №3(104). - pp. 179-186. (Занин В.Ю. Использование телеуправляемых подводных аппаратов (ТПА) со специализированных и неспециализированных плавсредств // Известия ЮФУ. Технические науки. 2010. №3(104). - С. 179-186.)

[6] Filaretov V.F., Konoplin A.Yu., Konoplin N.Yu., Gorbachev G.V. (2016). Control system for underwater vehicle with multilink manipulator for automatic manipulation operations, Proceedings of the 27th DAAAM International Symposium, B. Katalinic (Ed.), Published by DAAAM International, Vienna, Austria, 2016, - pp. 714-720. DOI: 10.2507/27th.daaam.proceedings.103.

[7] Filaretov V.F., Konoplin A.Yu., Konoplin N.Yu. (2017). System for automatically performing of manipulation operations with help of underwater robot. Mechatronics, automation, control. 2017. Iss. 8. - pp. 543-549. (Филаретов В. Ф., Коноплин А.Ю., Коноплин Н.Ю. Система для автоматического выполнения манипуляционных операций с помощью подводного робота // Мехатроника, автоматизация, управление. 2017. №8. T. 18. C. 543-549.)

[8] Filaretov V.F., Konoplin N.Yu., Konoplin A.Yu. (2017). Approach to Creation of Information Control System of Underwater Vehicles // Proceedings of IEEE 2017 International Conference on Industrial Engineering, Applications and Manufacturing (ICIEAM), S.-Petersburg, Russia. - pp. 1-5. 